\title{
Contratos Internacionais e Comércio Exterior com a URSS.
}

\author{
Guido $S$. Soares \\ Professor Assistente Doutor da Faculdade de DI- \\ reito da Universidade de São Paulo e da Pontifícia \\ Universidade Católica.
}

O fato de a comércio entre as Nações realizar-se num contexto insusceptível de ser dominado por regras jurídicas de um único país, traz importantes consequiências ao estudo e à prática de contratos que versam sobre relações mercantis internacionais.

A interpenetração de soluções jurídicas baseadas em sistemas ideológicos conflitantes, a presença de pelo menos dois esquemas normativos opostos pelos valores de base, mas parcialmente unificados na existência de tratados e contratos válidos entre as partes, tornam as considerações sobre o comércio entre nações, de um lado as de economia centralmente planificada, e de outro, as de economia de mercado, duplamente importantes para o Direito; permitem:

a) a descoberta de normas extra-estatais que trancendem as posiçães ideológicas das partes e que refletem a verdadeira vocação ecumênica do Direito Internacional, como normatividade, fonte e raíz da convivência entre as nações e principal causa da paz;

b) a averiguação de normas comuns presentes em sistemas opostos, que possibilitam a formulação de um código de conduta, objetivo e prático, que à semelhança de uma Gramática Transformacional presente em qualquer lín- 
gua, ensejaria maior conhecimento dos sistemas jurídicos em comparação e melhor formulação de soluções de conflitos.

Enfim, há o interesse imediato nos dias presentes de se conhecerem os elementos novos trazidos ao Direito Internacional, com a crescente tendência dos Estados, por eles próprios ou através de empresas em que participem direta ou indiretamente, praticarem um comércio não-tradicional, ou seja, sujeito a riscos e insusceptível de contar com posições privilegiadas. $\mathrm{O}$ Estado comerciante na verdade não poderia invocar suas imunidades em atividades da rotina do comércio internacional, sem causar grande insegurança no mundo dos negócios, e por tal motivo, tem o Direito Internacional buscado novas fórmulas com que se assegure o papel privilegiado dos Estados nas relações mercantis internacionais, bem como a proteção de interesses individuais. De particular importância, o exame das relações comerciais internacionais com os países de economia centralizada, tem enriquecido os capítulos da teoria da imunidade de jurisdição dos Estados, e das soluções pacíficas de controvérsias, em especial, das soluções não judiciárias, tais como o recurso à arbitragem comercial internacional. Escolheu-se a uRss como exemplo, porque, sem sombra de dúvida, é o país de economia totalmente centralizada que apresenta uma teoria mais desenvolvida dos contratos de comércio internacional, em virtude de sua reiterada prática nas trocas mundiais. Neste estudo, não serão considerados os aspectos de transferência de tecnologia nem de assistência técnica (que envolvem as importantes questões da proteção da propriedade industrial e intelectual), mas somente os aspectos relacionados com os contratos de compra-e-venda internacional, por serem os atos mais importantes do comércio exterior dos paises, em geral.

A primeira questão que se coloca é de saber como, numa economia onde as atividades de comércio exterior são monopólio do Estado, se definem as pessoas que integram a relação 
jurídica contratual externa. Com efeito, já desde os primeiros atos do poder revolucionário de Outubro de 1917, o comércio na URss se tornaria atividade estatal, portanto em coerência com a ideologia que se impunha ao país.

Pelo decreto de 22 de abril de 1918, artigo primeiro, todo comércio exterior da URSs foi nacionalizado e "as transações comerciais ambas as atividades de compra e venda de quaisquer gêneros de produtos (da indústria mineira, da indústria de manufaturas, da agricultura, etc.) - com governos estrangeiros e com empresas comerciais, no exterior, serão executadas no nome da República Russa, por orgãos especialmente dotados de poder para tal" "Todas as transações comerciais com paises estrangeiros, ambas, a importação e exportação, são proibidas, exceto se levadas a cabo por tais orgãos "'. Tais disposições se acham reproduzidas no artigo 11 da Constituição da urss de 1936.

O monopólio estatal soviético, por imposição constitucional, traz algumas conseqüências nos sistemas das tratativas contratuais, capacidades das partes e nos limites legais das responsabilidades das partes. Por tais razões é necessário examinar a estrutura das entidades soviéticas especializadas em comércio exterior, que, para efeitos legais, não se confundem com o Estado soviético.

Na vigência do NEP (Nóvîe Economitcheskyi Plan), transigência com alguns dos princípios do socialismo, em favor de certos príncipios capitalistas, que no dizer de Lenin representaria "dar um passo atras para poder dar-se dois à frente", houve um relaxamento geral do monopólio estatal nos primeiros dias da Revolução de Outubro, através de um siste-

1. Decreto Nacionalizando o Comércio Exterior (UrSS), apud GIFren, James Henry. The legal and practical aspects of Trade with the Soviet Union. New York, F. Praeger Pub., 1969. Apêndice CC, p. 314. Doravante referido, simplesmente, como Giffen.

Os textos citados de linguas estrangeiras foram livremente traduzidos pelo autor. 
ma de licenciamentos, "pelos quais as empresas constituídas pelo Estado concederam licenças a cidadãos particulares e empresas $^{2}$, para livremente comerciarem com o exterior e atıavés da criação de ramos do Comissariado do Comércio Exterior, que tomaram a forma de delegações comerciais e agências ou, em poucos casos de empresas criadas no exterior" ${ }^{3}$ segundo leis do país em que se constituíssem ${ }^{4}$. Nos finais dos anos 20 e inícios dos 30, o sistema foi substituido por outro que se descartou do setor privado e concedeu às empresas estatais autonomia para poderem contratar no exterior, independentemente de qualquer supervisão das delegações comerciais, sendo estas últimas, aos poucos, assimiladas a repartição das embaixadas soviéticas, no exterior. Pouco antes da Segunda Guerra Mundial, houve uma grande simplificação da organização soviética do comércio exterior, em especial devido às necessidades de expansão das relações mercantis da URSS com o resto do mundo.

$\mathrm{Na}$ atualidade, o comércio exterior da uRss é coordenado a controlado pelo Ministério do Comércio Exterior, que, juntamente com 3 outros orgãos econômicos do governo soviético, o Comitê Estatal para o Planejamento (Gosplan, sigla para Gossudarstvenii Plan), e o Banco Estatal (Gosbank, sigla para Gossudarstvenii Bank), constitue um dos vários orgãos do Conselho de Ministros, "o mais alto orgão executivo e administrativo do poder estatal da URSs", conforme reza a Constituição da uRss (1936), no seu artigo 64. Sob o controle do Ministério do Comércio Exterior, encontram-se 4 categorias de agências especializadas: a) a Câmara de Comércio da URSS; b) as organizações do comércio exterior (combines); c) as delegações comerciais no exterior e d) empresas de co-

2. Fensterwald JR., Bernard. Sovereign immunity and Soviet State Trading. Harvard Law Review, Cambridge, Mass., 63:628, 1950. Doravante referido, simplesmente, como Fensterwald.

3. Id., ibid., p. 628 .

4. Citem-se, a exemplo, a ARcos, criada na Grä-Bretanha e a AMTorg, nos EuA. Quanto a esta última, veja-se mais além. 
mércio exterior, de propriedade da uRss e por ela dirigidas, criadas segundo normas dos países em que se constituiram.

As organizações de comércio exterior (COMBINEs) ${ }^{4 a}$ são criadas por decreto do Conselho de Ministros da URSS e têm autoridade para importar ou exportar uma categoria específica de mercadoria. São pessoas jurídicas de direito público interno soviético, com bens próprios e distintos dos do Estado, e, conforme o artigo 23 do Código Civil da República Federada da Russia "podem em nome próprio adquirir propriedades e direitos pessoais, serem sujeitas a responsabilidades, serem autoras ou rés em todos os casos ajuizados em cortes (institucionais) ou tribu-

4.a Segundo HENRY PUGET (Les Institutions Administratives Etrangères, Paris, Dalloz, 1969, p. 139 e segts.), distinguem-se na sistemática da organização empresarial soviética, 3 tipos de entidades com personalidade jurídica definida: a) a empresa, unidade econômica de base, que pode agrupar diversas plantas industriais; é dirigida por um diretor, nomeado pelo ministério e pelo truste do qual depende; b) os trustes, organismos de administração econômica, que operam uma concentração horizontal de empresas da mesma natureza; são dirigidas por um presidente, assistido por um comitê diretor; c) as organizações (em russo, kombinat, fr., combinat e ingl. combine, na linguagem técnica dos economistas, em português, trustes verticais) que agrupam empresas que são reciprocamente clientes umas das outras, numa concentração vertical e têm uma direção colegiada, à semelhança dos trustes; apresentam-se como grandes unidades técnicas e econômicas, a exemplo, o Kombinat Ural-Donietz, que agrupa as minas metalúrgicas do Ural, as grandes siderúrgicas clientes de tais minas e as carboniferas do Donietz, produtoras do combustível e da matéria prima do aço e ferro. Na sistemática dos regimes de economia de mercado, os melhores similares da organização empresarial da URss, de regime monopolístico estatal, são fornecidos exatamente pela tipologia das leis anti-trust norte-americanas, que ao consagrarem os princípios de livre iniciativa, qualificam de ilícitos (civís, criminais e contra a livre concorrência) quaisquer práticas monopolísticas. Feitos os devidos reparos, a empresa soviética poderia ser assimilada a grandes sociedades mercantis que operam usinas relacionadas à produção de um único produto; os trustes soviéticos, às práticas de concentraçōes (ou contratos) de cooperaçăo entre concorrentes de um mesmo produto (horizontal restraints of trade) e "kombinati", às práticas de concentrações (ou contratos) verticais de firmas não necessariamente concorrentes em função dos produtos que fabricam, mas em função do produto final (vertical restraints of trade). Conforme ainda a tipologia das leis anti-trust norte-americanas, inexiste paralelismo com os "conglomerate mergers" ("acquisitions in an unrelated area or field") ou práticas oligopolísticas baseadas na diversificação total do capital, este último, fenômeno restrito à concentração típica dos países capitalistas. 
nais de arbitragem 56 Operam na base de um Estatuto que lhes fixa suas funções e os limites de suas responsabilidades (Código Civil russo, arts. 26 e 32). Comor regra geral, em qualquer Estatuto das várias organizações, há disposição particular que dispõe que a organização responde por seus atos e cbrigaçōes com suas propriedades, e nos limites de suas propriedades, contra as quais pode ser intentada execução na conformidade das leis em vigor na uRss" e que "o Estado, suas agências e outras organizações não. são responsáveis por atos e obrigações da organização", e ainda que, "a organização de comércio exterior da URSS não é responsável por reclamação contra o Estado, suas agências e outras organizações ${ }^{7 " \text { " Segun- }}$ do o art. 97 do Código Civil russo devem excluir-se dos bens susceptíveis de serem trazidos à colação, no caso de execução de uma organização de comércio exterior, "os edifícios estruturas e equipamentos e outros bens de capital das organizações estatais (que) não podem ser objeto de hipoteca (legal) ou serem executados para satisfazerem direitos de credores" $\mathrm{O}$ artigo 411 do. Código de Processo Civil russo ${ }^{8}$ reafirma o princípio de que "na ausência de recursos monetários das instituições, empresas e organizações estatais, suficientes para satisfazerem sua insolvência, a execução se fará na propriedade

5. Texto apud Law in Eastern Europe. São volumes de uma série de publicaçóes de doutrina e traduçóes de textos legais dos Países da Europa Oriental, publicados pelo Documentation Office for East European Law da Universidade de Leyden, Países Baixos, e editados por Z. Szirmai, pela A.W. Sijthoff, Leyden.

6. Vejam-se, além, as considerações sobre a importância relativa dos Códigos da República Federativa Socialista Russa (aqui abreviado para Códigos russos, da República Russa etc.). De imediato, note-se que, por ser a República da URss com maior prática de comércio exterior, bem como pelo fato de ter sído, sempre na história da Unss ou do Império russo o centro cultural, científico e político do país, suas leis tendem a servir de modelo para as outras unidades políticas da URss.

7. Estatuto da Organização Federal para a Importaçãoe Exportação de Produtos Alimentícios de Ordem Animal (ProdiNTorg), publicado em "Vnieshniaía Torgovlia" (Comércio Exterior), publicação oficial do Mínistério do Comércio Exterior da URSS, citus apud JoHn N. Hazard, I. Shapiro e P. Maggs, The Soviet Legal System, ed. revista, Parker School of Foreign and Comparative Law, Oceana Pub., Inc., Dobbs Ferry, N. York, 1969, p. 253.

8. Texto apud Law in Eastern Europe, 11 (V. Nota 5) 
pertencente ao devedor, tal julgado, com exceção de empresas, edificações estruturas, equipamentos e outros bens que formem parte de seus recursos básicos, sementes e implementos agrícolas, bem como outros fundos circulantes necessários para a operação normal das instituiçōes, empresas e organizações estatais"

As delegações de comércio exterior soviéticas são representantes das organizações de comércio exterior no estrangeiro, com capacidade de agir como agentes das mesmas. Podem revestir a forma de delegaçōes "ad hoc", na representação das organizações em feiras internacionais ou em missões especiais para a conclusão de acordos comerciais com governos ou empresas estrangeiras, ou ainda, a forma de delegações permanentes nas principais cidades dos países com os quais a URSs mantém relações diplomáticas. Tais delegações permanentes não têm personalidade jurídica, e, sendlo uma ramificação direta do governo soviético, podem sempre invocar a questão de sua imunidade de jurisdição, frente aos empresários públicos ou privados dos sistemas que adotam uma estrutura jurídica baseada numa economia não centralmente planificada.

Um exame do "Status" de tais delegações de comércio exterior soviéticos revela, a partir do tratamento a elas dispensado nos vários países não pertencentes ao bloco socialista, duas situações. A primeira, da legislação norte-americana, considera-as como entidades que "deverão exercer as funções rormalmente atribuídas a um "attaché" comercial ou repartição de embaixada ("counselor"), ou seja, a coleta de informações econômicas e comerciais, o estudo das condições de mercado, a promoção e o fomento de relações comerciais c outras atividades análogas ${ }^{9}$ sendo, entre os governos claramente estabelecido que "tal funcionário ou organização"

9. Memorandum do Departamento de Estado à Embaixada soviética em Washington (701.61111/744) de 20 de dezembro de 1933, conforme Foreign Relations of the USA, Diplomatic Papers, 1933, v. II, p. 829, publicação oficial do Secretary of State, US Government Printing Office, Washington D.C., 1949. 
não deverá engajar-se em quaisquer transações comerciais, de qualquer espécie, ou seja, não deverá participar de negociações comerciais ou assinar contratos com firmas norte-americanas, em operações de compra e venda etc ${ }^{10}$ A fim de ultrapassar as proibições de negociar nos EuA, assim como de evitar os embaraços criados pelas imunidades diplomáticas nos negócios realizados numa economia extremamente liberal, como agentes das organizações de comércio exterior, "a URSS estabeleceu uma organização de comércio exterior segundo as leis de Nova York, conhecida como Amtorg Trading Corporation. empresa de Nova York, (que) possui uma personalidade jurídica separada e distinta, que é sujeita às leis de Nova York e, portanto, não pode escapar à responsabilidade civil a pretexto da teoria de imunidade de soberania ${ }^{11}$; sua função é a de agir como agente e mandatário de cada organização de comércio exterior soviético nos EuA, sendo que, em cada contrato, a fim de claramente determinar seu papel de presentante, a AMTORg assina como segue: "For and behalf of the. . (comprador ou vendedor) Amtorg Trading Corporation as agent only, By:.. ... , Vice-Presidente ${ }^{12}$.

A segunda situação é aquela que se apresenta no Brasil, criada com o Protocolo Brasil-Urss firmado em 20 de abril de 1963 no Rio de Janeiro (no mesmo dia em que se firmava o Acordo de Comércio e Pagamentos entre ambos os países) ${ }^{13}$, bem como com o Acordo sobre o Estabelecimento de um Escritório para fins Comerciais no Rio de Janeiro, concluído, por toca de notas, em 22 de setembro de $1972^{14}$

10. Memorando do Departamento de Estado à Embaixada Soviética, id.

11. GIFFEN, p. 118.

12. GIFFreN, p. 118 (itálicos não são do original) .

13. Os textos mencionados se encontram, respectivamente: a) o Protocolo Brasil-Urss de 1963, no Recueil des Traités das Nações Uniđas, 1968, (Registro n. ${ }^{\circ}$ 9257) p. 278 ss; b) o Acordo de Comércio e Pagamentos, apenso ao Decreto n. ${ }^{\circ} 56.521$ de 29 de junho de 1965, D.o.v. de 2 de julho de 1965 (Coleção de Atos Internacionais do Ministério das Relações Exteriores, n.० 507).

14. Notas reversais trocadas em Brasilia, a 22 de setembro de 1972. O Acordo entrou em vigor nesse mesmo dia e fol publicado no D.o.U. de 2 de outubro de 1972 (Coleção de Atos Internacionais do Ministério das Relaçōes Exteriores, $\left.n .^{\circ} 706\right)$. 
A regra básica é fixada no Artigo $4 .^{\circ}$ do Acordo de Comércio e Pagamentos Brasil-Urss de 1972, segundo a qual, "a execução dos contratos comerciais, concluidos sob o regime do presente acordo, não envolverá a responsabilidade dos 2 governos, ou de outras pessoas, físicas ou jurídicas, salvo nos casos em que sejam partes intervenientes em tais contratos". Mais claramente, o Protocolo, ao transformar a "Delegação Comercial Soviética no Brasil" em Representação Comercial da URss no Brasil determinou ser esta parte integrante da Émbaixada da Urss no Brasil e, portanto, suas instalações gozarem dos mesmos privilégios e imunidades concedidas às instalações das missões diplomáticas estrangeiras no Brasil, estando elas isentas da aplicação de leis e regulamentos brasileiros sobre o registro comercial (Art. $\left.1 .^{\circ}\right)$. Com as funções definidas no artigo $30^{\circ}$ do Protocolo, de promover a expansão do comércio entre a URss e o Brasil, de representar os interesses da Urss no Brasil, no que se refere ao comércio entre os dois países e de exercer, em nome do governo da URSS o comércio entre os dois países, "expressis verbis" os artigos $4 .^{\circ}$ e $5 .^{\circ}$ do Protocolo traçam os limites da imunidade de jurisdição da Representação Comiercial, que é o nome pelo qual se chama a delegação permanente de comércio exterior soviética no Brasil:

\section{Artigo 4}

A Representação Comercial atua em nome do Governo da URSS.

O Governo da Unss assume, pois, a responsabilidade por todas as transaçães comerciais que, no Brasil, forem concluidas ou garantidas pela Representação Comercial, mediante a assinatura dos documentos respectivos por duas pessoas devidamente credenciadas.

A Representação Comercial comunicará ao Governo brasileiro os nomes das pessoas que credencie para esse fim, bem 
como a extensão dos poderes que lhes confira, no tocante a quaisquer obrigações comerciais assumidas em nome da Representação Comercial. O Governo brasileiro publicará no Diário Oficial dos Estados Unidos do Brasil os nomes das pessoas designadas, bem como a extensão dos poderes que lhes hajam sido conferidos Tais poderes serão considerados válidos até que, no Diário Oficial, seja publicada notícia de sua revogação ou alteração.

Fica entendido, entretanto, que, quando não houver tal garantia da Representação Comercial - no caso de transações concluidas por Organizações soviéticas com personalidade jurídica autônoma, segundo o Direito soviético - serão responsáveis por essas transações, apenas, as Organizações soviéticas autônomas que delas participarem, as quais por elas responderão com seus bens e propriedades. Nesses casos, nem o Governo da URss, nem a Representação Comercial, nem qualquer outra Organização soviética autônoma que não seja parte na transação, por elas assumirá a responsabilidade.

\section{Artigo 5}

A Representação Comercial goza dos privilégios e imunidades que lhe são conferidos no Artigo 1, com as seguintes exceções:

1. As questões surgidas de transações comerciais, concluidas ou garantidas no Brasil pela Representação Comercial, nos termos do parágrafo $2 .^{\circ}$ do Artigo 4, serão da competência da Justiça brasileira caso não haja estipulações sobre a arbitragem, ou outra em contrário nos contratos específicos, ou as partes interessadas cheguem a entendimento diverso a respeito. Não caberão, nesse caso, medidas judiciais que impeçam a livre disposição dos bens de propriedade da Representação Comercial.

2. No que se refere aos procedimentos judiciais determinados pelos Tribunais brasileiros, de acordo com o dispos- 
to no parágrafo anterior, o Governo da URSS não invocará em favor do Chefe da Representação Comercial (o Representante Comercial), seus dois Suplentes ou demais funcionários da mesma, os privilégios e imunidades indicados no Artigo 2, ${ }^{14 a}$ e se compromete a autorizar o Chefe da RepresentaçãoC omercial (o Representante Comercial) e, na sua ausência, o Chefe substituto da mesma a representar o país, a fim de que o Tribunal possa proceder às medidas judiciais, de acordo com as demandas propostas nos termos do parágrafo anterior.

A execução das sentenças judiciais relativas às transações de que seja parte a Representação Comercial poderá incidir sobre todos os bens do Estado soviético no Brasil, particularmente sobre os bens, direitos e interesses, oriundos de transaçães efetuadas ou garantidas pela Representação Comercial. Não incidirá, porém, sobre os bens pertencentes às Organizações mencionadas no parágrafo $4 .^{\circ}$ do Artigo 4, que não houverem participado de transação garantida pela Representação Comercial.

Segundo a praxe internacional, não serão objeto de procedimento judicial de qualquer natureza, os bens e locais destinados exclusivamente ao funcionamento, no Brasil, da Embaixada, da Representação Comercial e do Consulado soviéticos, bem como os móveis e pertences nelas situados.

Posteriormente, com a transferência da Embaixada da URss para Brasília, e tendo em vista o permissivo constante

14a. Artigo 2 - O Chefe da Representação Comercial (o Representante Comercial), seus dois Suplentes e demais funcionários da mesma, que constarem da "Lista Diplomática", gozarão dos mesmos privillégios e imunidades que, segundo o Direito Internacional, são concedidos aos funcionários da Embaixada da URSS no Brasil. O número de funcionários da Representação Comercial estabelecer-se-á em entendimento à parte entre os dois Governos. Os cidadãos soviéticos enviados ao Brasil para servirem como funcionários da Representação Comercial estarão isentos do pagamento de imposto de renda sobre os sa lários que percebem do Governo soviético, pela execução das funçōes previstas no Artigo 3. 
no Artigo 1. ${ }^{\circ}$ do Protocolo de 1963, verbis: "a mudança das instalações da Representação Comercial de um local para outro ou outros locais, na cidade do Rio de Janeiro, bem como a criação de Seções em outros pontos do país, só poderá ser feita mediante prévio consentimento do governo brasileiro", a Representação Comercial da URSs passou sua sede para a Capital federal brasileira e no Rio de Janeiro foi mantido um "escritório para fins comerciais", segundo as condições tratadas entre os governos brasileiro e soviético (Acordo publicado no D.o.u. de 2 de outubro de 1972) Conforme o Acordo de 1972, o Escritório Comercial no Rio de Janeiro (e, outros que existam no Brasil) constitui uma seção da Representação Comercial da Urss no Brasil, esta com sede em Brasília. Com a função exclusiva de "fomento do intercâmbio comercial entre os dois países" ${ }^{15}$, às instalações e correspondência do Escritório é conferido o privilégio de inviolabilida$\mathrm{de}^{116}$ ao seu Chefe são conferidos os "privilégios e as imunidades geralmente concedidos aos Cônsules estrangeiros no Brasil" ${ }^{17}$ e os demais funcionários do Escritório, de nacionalidade soviética receberão tratamentos semelhantes aos atribuídos aos funcionários administrativos de Repartição Consulares estrangeiros no Brasil ${ }^{18}$.

Do que foi exposto, conclui-se que as delegações de comércio exterior soviéticas, quer se apresentem na forma de pessoas jurídicas de direito privado, organizadas segundo leis de países onde se encontrem, quer sejam partes integrantes das Embaixadas da Urss (Representações Comerciais) ou seções de tais partes integrantes (Escritórios Comerciais), são entidades meramente representativas das organizações de comércio exterior soviéticas (combines), tendo poderes para agir unicamente em nome das mesmas. Enfim, é necessário

\footnotetext{
15. Notas reversais trocadas em Brasília, a 22 de setembro de 1972. Nota brasileira, letra $b$.

16. Notas reversais (Brasilia, 22 de setembro de 1972), letra $c$.

17. Notas reversais (Brasília, id.), letra $f$.

18. Notas reversais (Brasília, ld.), letra $g$.
} 
dizer algo sobre a Câmara de Comércio da URss: organizaçāo com função similares às das Câmaras de Comércio dos países não socialistas mantém ainda a seu cargo a Comissão de Comércio Exterior e a Comissão de Arbitragem Marítima, além de ser responsável pela administração do sistema de registro de patentes estrangeiras ${ }^{19}$

A fim de poder resolver disputas surgidas sobretudo nos contratos de comércio exterior com empresários privados dos países capitalistas, e dado ao fato de contar com "técnicos" de vários ramos industriais e com a participação de advogados altamente especializados, a arbitragem governamental (soviética) se desenvolveu no sentido de um verdadeiro sistema de cortes comerciais ${ }^{20}$, na expressão do Professor norte-americano K. GrzYbowski. Aceitando com reservas tais afirmações, pela ambigüidade do que possam ser cortes comerciais num país onde só o Estado comercia com o exterior e onde inexistem mesmo juízes administrativos ou comerciais ${ }^{20 a}$, bem como pela inadequação de considerar as arbitragens como procedimentos instituídos em cortes comerciais (sabendo-se que nestas, quando existentes, a jurisdição é extracontratual, automática e, nas arbitragens, a jurisdição é contratual, dependendo, assim, da validade do contrato ou cláusula compromissória, ou ainda do compromisso arbitral), $\epsilon$ forçoso reconhecer que num sistema rígido, onde a cada passo o comerciante estrangeiro se veja às peias com o aparato estatal, carregado de imunidades e prerrogativas, procure-se determinar regras de conflito que, de um lado sejam coerentes com a realidade do monopólio estatal soviético do comércio exterior e, de outro, conducentes a permitir

19. Veja-se Giffen, sobretudo p. 115 e segts.

20. GrzyвowkI, Kazimierz. Soviet Private International Law. Law in Eastern Europe, 10 (vide nota 5), p. 41. Doravante referido como Grzybowski, simplesmente.

20a. A URss, em matéria de Direlto Administrativo, "somente conta com juízes judiclários e limita estreitamente os casos em que podem ser invocados (em tais assuntos)", conforme HENRY PUGET: Les Institutions Administratives Etrangères, Paris, Dalloz, 1969, p. 25. 
maior intercâmbio de uma economia necessitada de contactos com o resto-do-mundo. E neste ponto que o exame dos contratos internacionais de comércio exterior com a URSS representam vital interesse científico para o Direito Internacional Público e Privado.

Quanto às regras de conflito de leis em matéria de contratos, a URSS apresenta um certo paralelismo com o sistema dos Eua. As regras da "Conflit of Laws" norte-americana são de duas categorias: a) as baseadas no princípio da cláusula constitucional da "full faith and credit", pelo qual as leis, atos e sentenças judiciais dos Estados-membros da Federação gozam de igualdade absoluta em relação às leis, atos c sentenças judiciais do foro no qual são invocados ou trazidos à execução e b) as baseadas no princípio da "common law" pelo qual as leis e sentenças estrangeiras gozam do mesmo status que as similares dos Estados-membros da Federação, quando invocados no território dos EUA. As primeiras, de grande perfeição jurídica, elaboradas pela jurisprudência e compendiadas na atualidade no Restatement (Second) Conflict of Laws (1971), consagram regras definidas para o conflito de leis entre os Estados-membros da Federação, cada qual com grande autonomia para elaborarem suas regras de direito material, processual e conflitual; a exemplo, em matéria de contratos, o princípio dominante é o de que o contrato deve reger-se pela lei do Estado que tenha "the most significant relationship to the transaction and the parties (\$188), se outra lei não tiver sido escolhida pelas partes (\$187-1) e Baffin Land Corp. v. Monticello Motor Inn. Inc. (425 P 2d. 623), verbis: "where no choice is made, it is most likely that the parties would expect the law of the state with the most significant contact to be applied" As segundas, menos precisas que as primeiras, se têm formado a partir de uma interpretação judicial analógica dos precedentes julgados nas cortes norte-americanas, estendendo-os à situações internacionais; a exemplo, ainda citado caso de contratos, os juízes de Nova York têm lido a sentença em 
Mc GeE v. International Life Insurance Co. (325 US 220) (um tribunal da California reconheceu sua jurisdição sobre uma companhia de seguros do Texas, sem qualquer escritório ou agente na Califórnia e cuja única relação com o foro era uma apólice de seguro de vida, objeto do litígio, remetida pelo correio a uma pessoa domiciliada na Califórnia), como aplicável a qualquer situação em que haja um contrato conectado com uma das várias leis dos Estados-membros da federação, no sentido de estabelecer a jurisdição das cortes norteamericanas.

Ao igual que os Eva, a URss tem um sistema federativo que permite autonomia das unidades políticas internas no que respeita sobretudo ao Direito Civil e Processual Civil, dada a variedade dos povos que habitam seu território. Se bem que o Direito das Obrigações na parte dios contratos seja na URss bastante restrito para os particulares, em princípio haveria grande autonomia das Repúblicas da União de legislarem diferentemente na matéria, e na realidade, há mesmo a possibilidade de diferenças para as disposições nos contratos entre empresas estatais nas suas relações. Por tais razões, a URss passou leis de caráter supremo, os Fundamentos da Legislação da Unss e das Repúblicas da União, em 1961, que estabelecem os padrões mínimos e uniformes para as legislações a serem baxadas pelas Repúblicas da União (e relembre-se que a República Federal Socialista Soviética Russa é ela mesma uma federação). Os Fundamentos têm pois a dupla função de dirimirem conflitos entre a legislação da Uniäo e das Repúblicas da União e entre estas, e de conterem normas cujo destinatário é exclusivamente a URSs, naquelas matérias de sua competência reservada, das quais, como se referiu, se conta o comércio exterior ${ }^{21}$. A prevalência dos

21. Os textos dos Fundamentos da Legislação Civil da URss e das Repúblicas da Untăo, bem como dos Fundamentos da Legislaçāo de Processo Civil da Urss e das Repúblicas da Uniáo, junto com outros textos de direlto unlPorme da Unss encontram-se em Fundamentals of Legislation of the URss and the Union Republics, Moscou, Progress Pub., 1974. O texto dos Fundamentos da Legislaçăo Civil da Urss...é o v. 7 da Law in Eastern Europe (vide nota 5 ). 
Fundamentos sobre as leis das Repúblicas da União se baseia no princípio constitucional do art. 20 da Constituição da URSS (1936), que define a supremacia das leis da União sobre as das Repúblicas da União.

Sendo assim, no que se refere a contratos, dos Fundamentos da Legislação Civil da URss. podem extrair-se dois conjuntos de regras de Direito Internacional Privado: a) as aplicadas unicamente no território da URss, aos contratos conectados com leis divergentes das Repúblicas da União e que consagram os princípios da lei do lugar da conclusão do contrato, para regular a capacidade das partes, da locus regit actum para as formalidades extrínsecas do ato e da lex loci contractus (da conclusão dos contratos) para os efeitos das obrigações, se esta não tiver sido afastada por lei ou estipulação válida entre as partes (lex voluntatis), conforme seu art. 18 parágrafos 2 e 3; b) as aplicadas aos contratos internacionais, que se baseiam nos princípios do art. 3..$^{\circ}$ dos Fundamentos da Legislação Civil da URss. verbis: "As relações de comércio exterior são regidas pela legislação especial de comércio exterior da URSS e pela legislação civil geral da URSS e das Repúblicas da União", isto quer dizer, por legislação federal especial, pelos Fundamentos da Legislação Civil da União. ., no seu capítulo final e, subsidiáriamente, pelos Códigos das Repúblicas da União. E necessário acrescentar às normas de conflitos de leis aplicadas unicamente aos contratos internacionais, ao lado das leis soviéticas internas, "acordos internacionais com outros Estados, o costume internacional, a legislação internacional e a prática dos tribunais, em particular, as regras das Comissões de Comércio Exterior e de Arbitragem Marítima ${ }^{22 \%}$

O contrato internacional é definido pelo Professor soviético LuNZ: "one - at least - of the parties to this contract, as well as one - at least - of the parties to any other foreign

22. GRZYво wsKI, p. 45. 
trade transaction, is a foreign physical or juridical person 23" Dado o caráter de monopólio estatal do comércio exte-t rior da uRss, nada mais natural do que definir-se um contrato internacional como aquele caracterizado pela presença de um estrangeiro na relação jurídica. A questão da qualifícação do contrato pela caracterização de uma das partes, em especial pelo fato de ela ser estrangeira, que pode parecer uma revivescência da teoria medievalizante dos estatutos pessoais, é importante na legislação soviética, pelo menos, no que se refere à determinação da capacidade das partes.

De fato, sendo a parte soviética num contrato internacional de comércio exterior sempre uma organização de comércio exterior soviética (combine), cuja capacidade jurídicil é determinada segundo a lei soviética, a questão de determinar-se qual a regra aplicável a tal incidente é extremamente simples: a lei soviética regulará a situação legal da parte soviética, os limites de sua responsabilidade quanto a propriedades com que pode responder, assim como "a forma de transações comerciais celebradas por organizações soviéticas e o método de sua assinatura" . . irrespectivamente do lugar da transação (Fundamentos da Legislação Civil da Urss... at. $125 \& 2^{\circ} .^{\circ}$. Uma transação efetuada por uma organização de comércio exterior soviética em discordância com os objetivos fixados no seu Estatuto é inválida (Código Civil russo, art. 50) e "cada parte deverá restituir à outra tudo o que recebeu, por efeito da transação, ou, na impossibilidade de restituí-lo em espécie, a pagar seu valor em moeda, a menos que outras consequiências da anulação do ato sejam fixadas por lei" (Fundamentos da Legislação Civil. art. 14 , repetido no art. 48 do Código Civil russo) ${ }^{24}$.

23. LUNZ, L.A. Conflict of Laws in International Sale: theory and practice of socialist countries. Recueil des Cours, Academia de Direito Internacional da Haia, 1965 , I, t. 114, p. 6. Doravante referido como Lunz, simplesmente.

24. Cr. com o art. 158 do Código Civil Brasileiro, que sofreu as mesmas influências do BGB alemão, igual fonte inspiradora do Código Civil russo. 
$\mathrm{Na}$ legislação soviética, o ato jurídico nulo por dolo bilateral acarreta a reversão ao Estado de tudo quanto foi recebido, por força de uma transação que é conscientemente relacionada com um objeto oposto aos interesses da URSS ou do público; o dolo unilateral acarreta a reversão parcial somente no que respeita à parte que cometeu o dolo (Fundamentos da Legislação Civil... art. 14, repetido no art. 40 do C. Civil russo). Tais regras têm poucas aplicações nos contratos internacionais, pois sendo a parte soviética uma organização estatal, presumivelmente deverá agir conforme a lei; mesmo admitindo tal presunção, poderia haver argüição de incapacidade da parte soviética ou estrangeira ou ainda dolo unilateral desta última; segundo a doutrina soviética, "os tribunais soviéticos e os árbitros governamentais evitam a $\mathrm{pu}$ nição por confisco, inclinando-se, antes, pela aplicação de multas, sendo estas consideradas punições mais efetivas que 0 confisco..." e quando. . a aplicação de medidas punitivas não é considerada necessária as autoridades juridiciais se contentam com a restituição a cada parte dos bens entregues ou pagamentos efetuados entre as partes ${ }^{25}$.

Conforme as regras de Direito Internacional Privado soviéticas, a capacidade contratual das pessoas jurídicas estrangeiras é determinada pela lei do lugar de sua constituição. (lex societatis) e não pela lei de sua sede social ou qualquer outra. Segundo o Professor Samuel Pisar, "não há um único caso (julgado) que ilustre a prática dos tribunais soviéticos em relação à capacidade das empresas estrangeiras". "Conclui-se a partir da atitude dos tribunais soviéticos em relação à capacidade das empresas domésticas e a partir do entusiástico "lip service" que a doutrina soviética empresta ao princí pio da lei pessoal, que a personalidade jurídica das empresas estrangeiras será reconhecida as questões relativas à sua capacidade serão submetidas à sua lei pessoal, que no Conflito de Leis soviético é a lei do lugar de sua constituição (verbis:

25. Conforme Professor Genkin, apud GRzxbowsiri, p. 78. 
which in Soviet Conflict of Laws is the law of the place of incorporation) ${ }^{28}$ Tais princípios são repetidos nos tratados bilaterais de comércio da URSS, com o Japão, 1957 (pessoas jurídicas japonesas são aquelas organizadas segundo a lei do Japão), com a França, 1953 (estabelecidas segundo a lei francesa), com a Suiça, 1958 (estabelecidas no território da parte contratante, de acordo com a legislação em vigor no mesmo território ${ }^{27}$, e com o Brasil, 1972 (art. VII do Acordo sobre Transportes Marítimos, concluido em Moscou, em 20 de outubro de 1972, promulgado pelo Decreto n. ${ }^{0} 72.676$ de 22 de agosto de 1973, D.o.u. de 23-8-73, verbis: "Companhias e empresas de navegação marítima constituidas no território de uma das Partes Contratantes...).

No que respeita à capacidade contratual de pessoas físicas estrangeiras, a regra é a do art. 122 dos Fundamentos da Legislação Civil da Urss e da República da União: "Cidadãos estrangeiros gozam na URss da mesma capacidade civil que os cidadãos soviéticos", sendo admitidas exceções por força da lei; gozam dos mesmos direitos processuais que cs soviéticos, concorrendo com esses em igualdade de condições, no que respeita a direito de acesso aos tribunais ( $F$ undamentos cla Legislação Civil, art. 59). Sendo assim e conforme o direito soviético, art. 11 do Código Civil russo, é capaz de adquirir direitos civis a ser sujeito à responsabilidade civil o indivíduo maior de 18 anos (se casado pode ser emancipado antes de tal idade) e não declarado incapaz por decisão judicial (C. Civil russo, arts. 15 e 16)

Apesar de a doutrina soviética e os textos legais insistirem em que "a forma de uma transação realizada no exterior é sujeita à lei do lugar da transação", apesar do fato de que "uma transação não será anulada devido à invalidade, se a forma prescrita pela lei soviética foi observada", em suma,

26. PISAR, Samuel. Soviet conflict of laws in International Commerclal Transactions. Harvard Law Review, Cambridge, Mass., 70: 645, 1975.

27. GrZYBowskI, p. 81. 
apesar da aparente adoção da regra universalmente aceita de que "lex loci regit actum" e do moderno princípio da validação dos contratos que contenham vícios de forma, a lei soviética nos contratos internacionais é extremamente territorial no que respeita às formalidades extrínsecas: "a forma das transações de comércio exterior realizadas por organização soviéticas e maneira de assinatura das mesmas são determinadas pelas lei da Urss (Art. 125 dos Fundamentos da Legislação Civil, art. 122 Fundamento de Legislação de Processo Civil da Unss. ) Tais leis existem, expressamente, e requerem a forma escrita e a assinatura de dois representantes das organizações soviéticas de Comércio exterior que são parte do contrato: o presidente da organização ou outro funcionário ou pessoa claramente designados para firmar o documento, com poderes especiais ${ }^{28}$; dispensam-se o registro em cartório ou outra forma tabelioa. Importante observar que tais disposições não se aplicam a cheques ou letras de câmbio, para os quais são válidas as disposições substantivas e conflituais das Convenções de Genebra de 1931 e 1936 uma vez que a URSS é parte do regime uniforme internacional.

Segundo os Fundamentos da Legislação Civil da URss art. 126, a lei do contrato (lex causae) é a lei do lugar da transação (lex loci contractus), a menos que as partes disponham de maneira diferente (lex voluntatis) Verbis: "os direitos e deveres das partes numa transação de comércio exterior são definidas pelas leis do lugar da transação de comércio, salvo disposição das partes em contrário.

Ora, conforme disposição do art. 124 dos Fundamentos da Legislação Civil da Urss. (que permitem empresas estrangeiras firmarem contratos no território da URSS, conjugado com os arts. 162/164 do Código Civil russo (que repu-

28. Decreto do Comitê Central Executivo do Conselho dos Comissários do Povo de 26 de dezembro de 1935, citus apud GIFren, p. 169, que é repetido no Código Civil russo, art. 44. 
ta o contrato concluido no momento do recebimento da aceitação das propostas pelo proponente) os direitos e deveres das partes num contrato internacional serão sempre regulados pela lei soviética, se o contrato for concluido em Moscou (domicílio das organizações de comércio exterior) se não houver cláusula de eleição da lei aplicável ou se esta for inváli$\mathrm{da}^{29}$ ou ainda se a lei escolhida for afastada por ofender à ordem pública soviética ${ }^{30}$

No que se refere à questão da autonomia da vontade nos contratos internacionais, segundo o Prof. Lunz, a liberdade irrestrita das partes de escolher a lei aplicável, diz respeito unicamente à lex causae ou seja, aos direitos e deveres das partes, e não se aplica a determinação das capacidades, condições de validade formal e aos efeitos in rlem do contrato. Dentro de tais limites a escolha pelas partes de um sistema legal estrangeiro pode resultar no afastamento de regras imperativas soviéticas, contando que isto não seja contrário a crdem pública (public policy), ou seja as bases da ordem social soviética, conforme indicado no art. 128 dos Fundamentos da Legislação Civil ${ }^{31}$. Na ausência da manifestação da vontade ou na sua anulação, a lex causae, como se viu confunde-se com a lex loci contractus, sendo o lugar do contrato determinado segundo o art. 126, $\$ 2 .^{\circ}$ dos Fundamentos da Legislação Civil "o lugar de conclusão do contrato será determi-

29. Tais implicações são importantes do ponto de vista da lei aplicável, especialmente nas transações entre ausentes. Por tais motivos, e a fim de afastar o automotismo na aplicação de uma lei desconhecida, torna-se estratégico sempre colocar, seja nas propostas de contrato ou na remessa de contra-propostas, cláusulas de leis aplicáveis aos contratos, bem como cláusulas arbitrais, pois, independentemente de sua validade, ou não pela lei brasileira, segundo a lei soviética, podem tornar-se disposiçóes válidas para um contrato internacional e a lei brasileira, se no caso a escolhida, vir a ser aplicável a um contrato internacional.

30. Art. 128 dos Fundamentos da Legislação Civil da URSs... "Limitaçóes à Aplicação da Lei Estrangeira. Uma lei estrangeira não será aplicada se sua aplicação contrariar os princípios fundmentais do sistema soviético".

31. LuNz, p. 32. Vide na nota anterior o texto do art. 128 mencionado no texto. 
nado segundo a lei soviética", portanto, o lugar ao qual se reporta o proponente, ao receber a aceitação de sua proposta ${ }^{32}$.

Duas questões diretamente relacionadas com a eleição pelas partes da lei aplicável aos seus direitos e deveres, são as cláusulas de eleição do foro e as cláusulas compromissórias de arbitragem, porque regidas pelo princípio da permissividade da autonomia da vontade nos contratos internacionais. Quanto ao do foro contratual, o art. 120 do Código de Processo Civil russo consagra sua possibilidade, com as proibições de afastar as jurisdições que se tornam exclusivas, nos seguintes assuntos, dentre outros: as ações contra transportadores nos contratos de transporte de bens de passageiros ou bagagens são ajuizadas no foro onde a administração da organização de transporte, à qual uma reclamação foi apresentada de maneira pré-estabelecida, esteja situada (art. 119 do C. Processo Civil russo). Note-se, contudo, que tais regras são válidas unicamente para os contratos inteiramente soviéticos e não para os de comércio exterior. $\mathrm{Na}$ verdade, inexistem textos de lei relativos ao foro contratual nos contratos internacionais, bem como procedente arbitral ou judicial que estabeleçam presunção de foro contratual, a partir da existência de eleição da lei aplicável ${ }^{33}$. Referindo-se a respeito da impossibilidade

32. Conforme o Professor LUNz, o mencionado art. 126 \& 2.0 fol redigido com a intenção de evitar conflitos de qualificação no que se refere ao momento de conclusão dos contratos entre ausentes, conflitos esses possíveis dada a existência do sitema da "Civil law" (conclusão no momento do recebimento da aceitação) ou do sistema da "common law (mail box system, ou seja conclusão no momento da expedição da aceitação). O Código Civil brasileiro, no art. 1086 caput parece adotar o sistema "common law", mas nas exceçōes dos itens I, II e III do mesmo artigo, parece adotar o sistema da "Civil law".

33. No direito soviético, como na maloria dos direitos continentais europeus, a cláusula de eleição da lel aplicável em geral náo se presume a partır de uma cláusula de eleição do foro. Na verdade, mesmo o sistema anglo norte-americano, tão ríco em matéria de conflito de jurisdição como capítulo do Direito Internacional Privado, repele tal presunção. Existe no Direito norte americano (Nova Iorque) o precedente de Lummus Co. $v$. Commonwealth Oil Refining Co. 280 F 2d. 915 que fez presumir a elelção de lel apliḉal a partir da escolha da lel da sede do Tribunal arbitral e o lugar da execução do contrato, e nāo automaticamente a partir de haver um foro de eleiçธo que poderia ter sido tomado com indicativo de elelçăo de uma lel aplicável ao contrato. 
de aplicar a regra locus regit actum nos contratos de compra-e-venda internacionais com a URSs, devido ao fato de que há um monopólio estatal envolvido, o Professor Lunz afirma que "as partes não podem, por exemplo, estipular a eleição de um sistema legal estrangeiro, a fim de limitar a aplicação das regras soviéticas que governam o comércio exterior ${ }^{34}$, concluindo GrzYBwSKr que tais princípios, obviamente se aplicam ao princípio da lex voluntatis: na prática soviética, a cláusula de eleição da lei aplicável ou possibilidade de aceitação de incompentência por virtude de cláusula de eleição do foro (the choice-of-law or change in court venue), devem estar conformes às provisões aplicáveis às determinações das condiçōes do contrato ${ }^{35}$

As cláusulas compromissórias e os compromissos arbitrais são bastantes comuns nos contratos de comércio exterior com a URSS. Na prática soviética utilizam-se três tipos de cláusulas compromissórias ou de compromissos arbitrais. No primeiro, qualquer divergência no que respeita a interpretação, validade ou rescisão do contrato ou interpretação ou modificação da cláusula compromissória ou do compromisso arbitral, são "submetidos à arbitragem à Comissão Arbitral do Comércio Exterior da URss, segundo as regras da Comissão". A sentença. será final e obrigatória. A submissão do litígio a outros Tribunais é excluida ${ }^{36}$ No segundo tipo, dependendo da nacionalidade do reclamante, o compromisso ou cláusula compromissória, podem enviar a questão seja à citada Comissão de Arbitragem de Comércio Exterior com sede em Moscou, ou a outra entidade comercial com sede no país da parte não-soviética; em ambos os casos, a sentença arbitral é proferida segundo as regras processuais do lugar onde os árbitros têm assento, sendo a sentença irrecorrível ${ }^{37}$. No terceiro tipo, se uma controvérsia

34. citus apud GRzYBowsir p. 90.

35. GRzYBowski p. 90 .

36. GTFFeN p. 358 e Apêndice PP, Typical Arbitration Clauses Used on Soviet Commercial Agreement.

37. Veja-se GIFreN p. 191 e 359. 
não puder ser resolvida por meios amigáveis, a disputa é enviada à arbitragem em um terceiro país qualquer, em geral a Suécia, após a parte reclamante haver notificado a outra sobre o objeto do litígio, com o nome e o endereço do árbitro de sua escolha. Dentro de, em geral, 14 dias, a outra parte tem o direito de indicar o segundo árbitro, e na eventualidade de não fazê-lo, o direito de indicá-lo reverte para o Presidente da Câmara de Comércio de Estocolmo (ou do país eleito entre as partes) Ambos os árbitros, em geral em 14 dias, escolhem o terceiro árbitro, e se não chegam a uma decisão, o direito de escolha reverte para a autodade comercial que escolheu ou que poderia ter escolhido o segundo. A decisão final é dada num prazo estipulado, em geral 3 meses, e tem efeito irrecorrível e final, com exclusão das vias inicial, paralela ou em grau de recurso aos tribunais judiciais ${ }^{38}$.

A sentença arbitral estrangeira na URss goza, no que respeita à sua executoriedade, do mesmo tratamento que as sentenças judiciais estrangeiras. O sistema é fixado no art. 63 dos Fundamentos da Legislação de Processo Civil da URSS, verbis: "o processo que governa a execução na URSS de julgamentos de cortes estrangeiras e juizos arbitrais serão determinados por acordos entre a Unss e países estrangeiros ou por convenções internacionais das quais a URss é signatária. Julgamentos de cortes estrangeiras ou juizos arbitrais podem ser apresentados para execução compulsória na URss, no prazo de três anos, a contar da data em que o julgamento se tornou final" No que se refere às Relações Brasil-URss, excluida a aplicação da Convenção para o Reconhecimento e Execução de Sentenças Arbitrais Estrangeiras (Assinada em

38. Giffen p. 191 e 360. No texto da Giffen de p. 191 há divergência da descrição dos fatos de p. 360. Segundo a prática internacional (veja-se, por exemplo J. Robert e J. Moread, L'Arbitrage, Paris, Ed. Y. Delmas, 1971; sobretudo Formules $\mathrm{Y}$ p.1 e sg.), no caso de a parte não reclamante deixar de indicar o segundo árbitro, o direito de fazê-lo reverter à Câmara de Comércio do $3 .^{\circ}$ país (no caso descrito por GifFen, a da Suécia, conforme p. 360) e não à parte reclamante (erroneamente descrito no texto de p. 191) . 
Nova York em 10 de junho de 1958), da qual o Brasil não ć parte ${ }^{39}$, as questões de arbitragem, no âmbito exclusivo de Transportes marítimos, se regem pelo art. IX do Acordo sobre Transportes Marítimos, concluido em Moscou a 20 de outubro de 1972, e promulgado pelo Decreto n. ${ }^{\circ} 72.676$ de 22 de agosto de 1973 (D.O.U de 23 de agosto de 1973), verbis: "As Partes Contratantes concordam em reconhecer qualquer cláusula arbitral ou acordo estipulando a decisão de submeter à arbitragem as controvérsias entre seus nacionais ou pessoas jurídicas decorrentes de questões relacionadas ao transporte marítimo ou à navegação, bem como assegurar a execução de laudos arbitrais, desde que: a) ambas as partes em litígio tenham concordado em submeter a referida disputa à arbitragem; b) o laudo se torne obrigatório para as Partes nos termos da lei do país em que o laudo tenha sido proferido; c) o laudo não seja contrário à ordem pública do país em que a execução seja solicitada. A execução do laudo: arbitral será regulada pela legislação do país no qual seja solicitada. A concordância em submeter controvérsias à arbitragem exclui a jurisdição dos tribunais" Assim sendo, nos termos do permissivo da legislação processual civil soviética, art. 63 in fine, conjugado com o mencionado art. IX do Acordo Brasil-Urss sobre transportes marítimos, o laudo arbitral, expedido na Urss ou no Brasil, ou alhures (mas envolvendo questões bilaterais Brasil-URss) respeitadas as condições das letras a, b e c do art. IX, é de execução compulsória na URss, inde-

39. São partes da “Convenção para o Rreconhecimento e Execução de Sentenças Arbitrais Estrangeiras" assinada em Nova Yorque em 10 de Junho de 1958: Austria, Bielorussia, Bulgária, Cambodia, Ceilāo, Equador, Filipinas, Finlândia, Finlândia, França, Gana, Grécia, Holanda, Hungria, India, Israel, Itália, Japão, Madagascar, Marrocos, Nigéria, Nigéria, Noruega, Polonia, RAd (Egito), Rep. Centro Africana, R.F. da Alemanha, Tranzania, Romênia, Suiça, Siria, Tchescoslovaquia, Tailândia, Trinidad, Tolago, Tunisia, Ucrania, Urss. UsA. Texto e informações apud Droit Interné et Internacional de l'Arbitrage, Robert J. e B. MOREAU (anexos 15, 16 e 17). Note-se que a Urss é igualmente parte da Convenção Européia sobre Arbitragem Comercial Internacional, assinada em Genebra em 21 de abril 1961, juntamente com a Austria, Bulgária, Bielorussia, Cuba, Tchecoslovaquia, R.F. da Alemanha, França, Hungria, Polonia, Rumania, Ucrania, Alto Volta, Yugoslávia e Itália (informação e texto apud J. Robert e B. Moreat, idem ibid., Anexos 18, usque ad 22). 
pendendo, pois, de homologação pela justiça soviética, valendo como "res judicata".

O Professor Lunz discute a natureza do compromisso arbitral e da cláusula compromissória, se puramente processual (e, sendo assim, resolvida pela lex fori) ou se uma disposição relacionada com a substância do contrato (e portanto submetida à regra aplicável à substância do contrato, lex causae, a ser indicada pela regra de conflito) citando exemplos dos sistemas anglo-americano e francês, em abono da primeira tese e exemplos germano-ocidental e italiano, em abono da segunda. Ouanto à posição soviética, em decisão da Comissão Arbitral de Comércio Exterior, formou-se jurisprudência arbitral no caso Oscar Mayer (Zurich) v. Compagnie Générale Interscambi (Milão) : examinada a validade de uma estipulação compromissória em favor de Moscou, numa disputa para reaver perdas e danos por atraso no pagamento de bens entregues ao comprador, no caso o réu italiano, a Comissão apoiou as razões deste último (nulidade de um contrato realizado na Itália, tendente a excluir a jurisdição dos tribunais italianos, se ambas as partes forem estrangeiras ou se uma das partes for italiana domiciliada no exterior, conforme art. 2. ${ }^{\circ}$ do Código de Processo Civil italiano), na base do art. 126 dos Fundamentos da Legislação Civil da Urss..., que consagra a regra da lex loci contractus para transações de comércio exterior ${ }^{40} \mathrm{Em}$ suma, segundo o precedente arbitral citado, na prática soviética a validade e a interpretação de um compromisso arbitral ou de uma cláusula compromissória devem ser qualificadas como matéria de substância do contrato, portanto submetida à lex causae, que no direito soviético é a lex voluntatis, ou na sua falta ou anulação, a lex loci contractus.

E interessante observar que a lex causae dos contratos de comércio internacional (direitos e deveres das partes), 
em geral é tratada como um todo, ou seja, como um conjunto de direitos e deveres recíprocos, submetido a um único sistema legal. Contudo, segundo o Prof. Lunz, o art. 126 dos Fundamentos da Legislação Civil da Urss... não pró́be às partes de poderem estipular leis especiais para deterininados efeitos do capítulo de direitos e deveres das partes. ${ }^{41}$. Note-se, pelo contrário, que a possibilidade de tratar de questões relacionadas à lex causae separadamente, fazendo-as regidas por leis diferentes, pode representar uma providência salutar para os negócios internacionais, quando se reconhece poder haver uma possível confrontação entre um negociador "performance minded", como o soviético, e outro, "breach minded" como o norte-americano ${ }^{42}$. For outro. lado, dividir a lex causae, a exemplo, colocando sob uma determinada lei as condições e garantias de pagamento, garantias de qualidade da coisa, provisões sobre inspeções, testes ou condições técnicas, e sob outra lei, as provisões sobre execução (performance), pode acomodar num só contrato diferentes mentalidades e diferentes circunstâncias que podem surgir do confronto entre sistemas econômicos e políticos divergentes ou ainda sistemas jurídicos que refletem diferentes graus de desenvolvimento econômico.

Finalmente, é necessário considerar a lei aplicável aos efeitos in rem do contrato de comércio internacional com a Urss, ou seja, a regulamentação do momento e da maneira da passagem da propriedade da coisa transacionada e dos efeitos legais de tal determinação (em especial, os relativos aos problemas da responsabilidade pela perda da res in transitu). Segundo o art. 30 dos Fundamentos da Legislação Civil da URSS.. "O direito da propriedade se transfere ao comprador da mercadoria, no momento da transferência da mercadoria, se não for estipulado de outra forma pela lei ou pelas partes" Ainda segundo o mesmo artigo, tal transferên-

41. LUNz, p. 42.

42. Expressōes bastante felizes de GrFres, p. 174 e ss. 
cia se pode operar: a) por tradição ao comprador; b) por entrega ao transportador para transporte por terra, mar ou ar, ou ao correio, para despacho, se inexiste obrigação de o vendedor entregar a coisa; c) por tradição do conhecimento de embarque ou de outros instrumentos negociáveis e que corporifiquem a coisa vendida.

No caso de conflitos de leis em contratos com a cláusula c.i.f., segundo o Prof. Lunz, a qualificação do momento da passagem do risco de perda da coisa se dá no momento em que os bens "realmente atravessam o parapeito do navio no porto de embarque ${ }^{43}$. Na verdade, na prática soviética, ainda segundo a mesma autoridade, dividem-se as duas questões: "a passagem do risco é um problema puramente contratual ${ }^{44}$, regulado pela mesma lei que determina a validade do contriato como um todo (lex causae) e a fortiori a validade das cláusulas c.i.f., f.o.b., f.a.s., f.o.t., etc."; a "passagem do título" é questão distinta e necessita uma definição do que se entende por passagem do título.

Sendo a Urss parte da Convenção da Haia sobre a Lei Aplicável à Transferência de Propriedade no caso de Venda Internacional de Objetos Corpóreos Móveis, de 1958, nos seus contratos internacionais de comércio exterior, "the proper law of the contract", ou seja, a lex causae, determinaria: a) o. momento em que se dá a passagem do risco de perda da coisa ao comprador; b) o momento até o qual o vendedor mantém seu direito aos benefícios provenientes do objeto vendido; c) o momento em que o direito de reclamar perdas e danos com respeito aos objetos vendidos passa ao comprador; d) a validade substancial da cláusula de conservação do título em favor do vendedor ${ }^{45}$ O Professor Lunz acrescenta, ainda, a regra do art. 12 do. Código de Direito Internacional Privado da Tchecoslováquia, em que pese a possibilidade de uma

43. LUNz, p. 48 .

44. LUNZ, p. 49.

45. Veja-se Lunz, p. 11 e 49. 
disposição interna de um país poder servir de regra in abstracto para outro ${ }^{46}$ : o momento em que o direito de dispor da coisa vendida se transfere para o comprador. Na doutrina soviética, na compra-e-venda marítima, o momento da passagem do título de propriedade, no caso de conhecimento de embarque ou de outros instrumentos negociáveis, é determinado pela lei do lugar do documento (situs cartae) ${ }^{47}$.

Definida a série de questões que se albergam na qualificação de passagem de título e, conforme dito anteriormente, tendo sido distinguido do que seja passagem de risco, e sendo ambos os assuntos submetidos à lex causae no direito soviético (lei escolhia pelas partes, ou a lex loci contractus), resulta válida a conclusão de que passagem do risco e passagem do título podem ser colocados sob o regime de diversas legislações, o que facilita o entendimentol entre as partes e soluções segundo sistemas diferentes ${ }^{48}$.

Ainda quanto a contratos, necessárias se fazem algumas considerações sobre os problemas relacionados com a imunidade de jurisdição do Estado soviético. Segundo já dito, as organizações de comércio exterior foram instituições surgidas após o NeP e após a final estatização do comércio exterior da URSS, exatamente para evitar as dificuldades do comércio com o resto-do-mundo, em função mesma das possíveis insusceptibilidades de execução forçada de contratos internacionais não cumpridas. Contudo, a URss, como qualquer Estado, pode gozar de imunidades de jurisdição em re-

46. Na ausência de lei soviética sobre o assunto particular, tendo em vista que o Art. 128 dos Fundamentos da Legislaçāo Civil da URSS... proibe a aplicação na URss de lei estrangeira se contradiz os princípios fundamentais do sistema soviético e considerando que a Tchecoslováquia é país de sistema político semelhante ao da URSs, prima facie nada impediria considerar o Código de Direito Internacional tcheco como aplicável, per se, nas relações Urss resto-do-mundo.

47. LUNZ, sobretudo, p. 50.

48. Na condição de que a parte não soviética igualmente considere os efeitos in rem do contrato submetidos à lex causae do contrato, com idêntica qualificação do que entenda por efeitos in rem (se năo for parte da citada Convenção da Haia de 1958). 
lação a seus bens e os bens de seus agentes no exterior, mesmo quando engajada em atividades puramente comerciais, na condição de tais atividades estarem situadas sob as regras das Convenções de Viena sobre Relações Diplomáticas (1960) e sobre Relações Consulares (1965) A distinção que vem ganhando corpo no Direito Internacional Público atual, entre atos praticados pelos Estados "jure imperii e os praticados "jure gestionis", de inspiração norte-americana, para conceder imunidade unicamente aos primeiros, não teria qualquer utilidade no Direito soviético.

$\mathrm{O}$ art. 61 dos Fundamentos da Legislação de Processo Civil da URss..., com efeito, dispõe: "Ações contra Países Estrangeiros" A fim de assegurar direito contra o mesmo e executar sua propriedade localizada na Unss só será permitido com o consentimento dos órgãos competentes do país envolvido. Os representantes diplomáticos de países estrangeiros acreditados junto à Urss e outras pessoas especificadas em leis e acordos internacionais serão sujeitas à jurisdição das cortes soviéticas em casos civis, unicamente nos limites determinados pelas regras do direito internacional e nos acordos com os países envolvidos. Nos lugares onde um país estrangeiro não concede ao Estado soviético, seus representantes ou sua propriedade, a mesma imunidade judicial que, de acordo com o presente artigo é concedida aos países estrangeiros, o Conselho de Ministros da Urss ou outro órgão autorizado, poderá impor medidas retaliatórias com respeito aquele país, seus representantes ou à sua propriedade ${ }^{49}$.

No que respeita ao direito marítimo soviético, "os juristas soviéticos e o Governo da URss mantêm a posição da total imunidade dos navios estatais da jurisdição estrangeira e da aplicação da lei estrangeira ${ }^{50}$. GRZYBowsKr, contudo, observa que "em anos recentes, as empresas de navegação

49. Texto em inglês, traduzldo llvremente pelo autor, apud Fundamentals of Legislation... (vide nota 21)

50. GrzyBowskI, p. 163. 
soviéticas, em casos de abalroamento, não têm invocado a imunidade de seus navios, quando apreendidos (in casibus Dutch) em águas territoriais ${ }^{51}$ ".Tal constatação é a exceção, permanecendo como regra para o comércio exterior da URSS o disposto no art. 13 dos Fundamentos da Legislação Civil da URss. . de que "as pessoas jurídicas são responsáveis por suas obrigações no limite dos bens que possuem (e as organizações estatais, dos bens a elas consignados) que, de acordo com a legislação da URsS e das Repúblicas da União sejam sujeitos à execução judicial"; e no caso do comércio externo, os bens consignados às organizações de comércio exterior e que constam como seus, nos respectivos estatutos.

Como conclusão, é necessário considerar como no Brasil são reguladas as relações de comércio exterior com a URSS. Em 1962, o Decreto 1880 de 14 de dezembro, criaria um Grupo de Coordenação de Comércio com o Leste Europeu (Coleste), diretamente subordinado ao então Chefe do Governo; reestruturado como Comissão de Comércio Exterior com a Europa Oriental (Coleste) pelo Decreto n. ${ }^{\circ}$ 62.225 de 5 de fevereiro de 1968, atualmente se rege pelo vigente Decreto 71.509 de 7 de dezembro de 1972, que revogou os anteriores.

À Coleste, com sede no Ministério das Relações Exteriores, compete, "respeitadas as atribuições do Conselho Nacional de Comércio Exterior, tratar de todos os aspectos das relações econômico-comerciais do Brasil com países e empresas da Europa Oriental, cabendo-lhe, entre outras, as seguintes incumbências: (art. 2. ${ }^{\circ}$ )

a) assessorar o Conselho Nacional de Comércio Exterior no exame dos assuntos relativos ao comércio com a Europa Oriental;

51. GRzyвоwskI, Kazimierz. The Merchant Shipping Code and the Soviet Union 1960. Law in Eastern Europe, 4, p. 121, nota 25 b, c1tus apud GrzYBowskI p. 174 nota 46 A (vide nota 20 hic). 
b) coordenar a negociação dos acordos, ajustes ou convênios relacionados com o comércio e os de cooperação técnica e econômica com a Europa Oriental;

c) preparar os trabalhos da Seção brasileira nas reuniões das Comissões Mistas previstas nos Acordos de Comércio entre o Brasil e a Europa Oriental;

d) acompanhar o registro no Banco Central dos contratos de financiamento de importações oriundas da Europa Oriental;

e) planejar, coordenar e promover - em articulação com órgãos de promoção comercial - a participação do Brasil $\mathrm{cm}$ feiras e certames de natureza comercial na Europa Oriental;

f) assessorar as autoridades competentes em assuntos relativos à participação de países ou empresas comerciais da Europa Oriental em feiras e exposições, individuais ou coletivas, no território nacional; e

g) incentivar a formação de consórcios e outras formas de associação de firmas brasileiras interessadas no comércio com a Europa Oriental.

Segundo o art. 3..$^{\circ}$ do Decreto 71.509/72, são membros permanentes da Coleste:

I - o Chefe do Departamento da Europa (Deu) do Ministério das Relações Exteriores, que exercerá a presidên$\mathrm{cia}^{52}$;

52. A denominaçăo de Secretário Geral Adjunto para Assuntos da Europa Oriental e Asia do M.R. Ext., que consta no Art. 3. I do Decreto 71.509/72, foi modificada para Chefe do Departamento da Europa (DEU), em virtude do art. 72 da Portaria do M.R. Ext. n.o 357 de 15 de março de 1973 (D.O.U. 19-3-73), que baixou o Regimento Interno da Secretaria de Estado das Relaçóes em cumprimento ao DL. 200/67 (Reforma da Administração Federal) e D. 71.534 de 12-12-72) (Estrutura Básica, Funcionamento e Competência do M.R. Ext.). Para o assunto em pauta, vide, da Portaria 357/73, em especial os arts. 72,74 e 75 . 
II - O Presidente da Comissão de Coordenação da Política de Coordeção de Compras no Exterior;

III - o Superintendente Geral de Vendas da Companhia Vale do Rio Doce, como representante do Ministro das Minas e Energia;

V - o Assessor Chefe do Conselho de Comércio Exterior, como representante do Ministro da Indústria e do Comércio;

VI - o Secretário de Cooperação Econômica e Técnica Internacional, como representante do Ministro do Planejamento e Coordenação Geral;

VII - o Gerente de Operações de Câmbio do Banco Central do Brasil;

VIII - o Chefe do Departamento Geral de Exportação da Carteira de Comércio Exterior do Banco do Brasil S/A.

$\mathrm{O}$ art. $3 .^{\circ}$ parágrafo segundo do Decreto $71.509 / 72$ dispõe que "a Coleste, por proposta de seu, Presidente, convocará para participar de seus trabalhos representantes de entidades privadas e públicas - federais, estaduais e municipais - cuja presença seja necessária ao desempenho de suas atribuições"

Do exame do mencionado Decreto 71.509/72, pode concluir-se que a Coleste é órgão de assessoria e planejamento das relações comerciais Brasil-URSs, sem poderes expressos de contratar em nome do Governo brasileiro contratos de comércio exterior com a URss, ou em nome de particulares ou de empresas da administração indireta federal ou estadual brasileiras. No caso: de contratos da União, Estados ou Municípios as negociações em geral se fazem via diplomática, preferindo-se contactos diretamente com o $\mathrm{Mi}$ nistério do Comércio Exterior em Moscou, e posterior acreditamento "ad hoc" de agente brasileiro para assinar os contratos. No caso da administração decentralizada ou de par- 
ticulares, a via pode ser contactar inicialmente a Representação Comercial da URss em Brasília ou dos Escritórios Comerciais existentes nos Estados, ou ainda contactos diretos em Moscou com o citado Ministério do Comércio Exterior. Tais observações finais advem da constatação de que, nos contratos de comércio exterior, na URSS a parte soviética é sempre uma organização estatal de comércio exterior, cuja personalidade e poderes de obrigar-se são clara e distintamente separadas do Estado soviéticio, ao passo que no Brasil, inexistem entidades unicamente dirigidas ao comércio exterior e que sejam estatais e com poderes assemelhados às organizações (combines) soviéticas. 